All letters are subject to editing and may be shortened. Letters should be sent to the BJGP office by e-mail in the first instance, addressed to

journal@rcgp.org.uk (please include your postal address). Alternatively, they may be sent by post as an MS Word or plain text version on CD or DVD. We regret that we cannot notify authors regarding publication. Letters not published in the Journal may be posted online on our Discussion Forum. For instructions please visit: http://www.rcgp.org.uk/bjgp-discuss

\section{The end of the NHS?}

Mike Fitzpatrick's article 'The end of the NHS?' in the March issue of BJGP starts with a quote 'What do you call a man who ignores medical advice? Mr Clarke'. ${ }^{1}$ That was the theme of one of the British Medical Association's (BMA's) posters used in its campaign of 1989/90 against Kenneth Clarke's so-called 'reforms'. The quote comes from Nicholas Timmins' book The Five Giants - a Biography of the Welfare State (page 471). ${ }^{2}$

Fitzpatrick continues with a completely unsupported and derogatory statement 'the BMA's pompous "doctors know best" slogan was a spectacular flop'. A casual reader may think that Timmins held that view. He certainly did not. On the contrary, Nicholas Timmins described our posters as 'of memorable brilliance!'. ${ }^{2}$ There was criticism of the poster by The Independent newspaper that I rebutted. ${ }^{3}$ It is also true that about 250 doctors left the BMA as a result of our poster campaign - about 2500 joined. Eighteen years later I revealed in my book The NHS: Beginning, Middle and End?, ${ }^{4}$ for which Nick Timmins wrote the foreword, my personal and private opinion that the 'Mr Clarke' poster was counter-productive.

Our campaign in 1989/1990 was remarkably successful. As early as 5 July 1989 The Guardian reported 'Mr Kenneth Clarke, the health secretary, last night admitted that the BMA was winning the propaganda war against his proposals for changes in the National Health Service. ${ }^{5} \mathrm{~A}$ year later, after the poster campaign, the Gallup Poll showed that $77 \%$ of people who were aware of the reforms disapprove of them. ${ }^{6}$
The next page (472) of Timmins' book reports how Mrs Thatcher 'got cold feet' as a result of our campaign and wished, for very good reasons, to delay the implementation of Kenneth Clarke's socalled reforms until after the next general election. Only the threat of resignation by Clarke prevented her from doing that. $^{2}$

Professor Alain C Enthoven, originator of Clarke's disastrous internal market, when giving the prestigious Rock Carling Lecture in 1999 said:

'The "big bang" approach to health services reform, be it internal market or PCTs, is a mistake. Too much is being wagered on too little knowledge of how it would work, even whether it could be made to work."

That has applied to each of the 'NHS reforms' since the first in 1974. There is no reason to think that Langley's mistake will do any better.

\section{John Marks,}

Chairman of Council British Medical Association 1984 to 1990 (Founder Associate of the RCGP).

E-mail: johnhenrymarks@btinternet.com

\section{REFERENCES}

1. Fitzpatrick M. The end of the NHS? Br J Gen Pract 2011; 61: 229.

2. Timmins N. The five giants - a biography of the welfare state. London: Fontana Press, 1996.

3. Marks J. Purpose of BMA advertising campaign. The Independent 1989; 1 Sep.

4. Marks J. The NHS: beginning, middle and end? - The autobiography of Dr John Marks. Oxford: Radcliffe Publishing, 2008

5. No Author Listed. Clark admits propaganda failing on NHS. Guardian 1989; 5 Jul: 24.

6. No Author Listed. More against health reforms. Times, 1990; 18 Apr.

7. Enthoven AC. In pursuit of an improving National Health Service. Rock Carling Lecture. London: Nuffield Trust, 1999.

DOI: 10.3399/bjgp11X567153

\section{Primary excision of cutaneous melanoma}

First, we would like to say that the National Institute of Health and Clinical Excellence skin cancer improving outcomes guidance (IOG), far from being arbitrary, was based on appraisal of a wide range of evidence. Regrettably, prior to the IOG, some high-risk skin cancer patients received treatment below an acceptable standard from less experienced practitioners, including curetted and otherwise incompletely excised melanomas, as well as melanomas that had been repeatedly frozen or simply misdiagnosed as benign. The IOG was intended to level up to best practice, and this has largely been achieved.

Results of the study by Murchie et al indicate that the GPs concerned carried out adequate excisions, ${ }^{1}$ but we are not told how many benign lesions were needlessly excised, nor is there information about quality of scars, follow-up, or other important factors. The IOG has delivered integrated services in which multidisciplinary teams provide evidence-based holistic care including follow-up, specialist nursing support, and patient education. Cutting out the lesion is only one part of the process.

The authors have included punch biopsies and incisional biopsies in their analysis of completeness of excision.

The number of incisional biopsies and punch biopsies in the secondary care group was significantly higher. It is in the nature of the biopsy that it is incomplete, therefore, they should have excluded this group of biopsies from the 
analysis. It would be interesting to reanalyse the data excluding this group of biopsy.

The rapid access pigmented lesion service in Aberdeen has undergone a significant reconfiguration since this study was undertaken. Therefore, conclusions drawn from this study cannot be compared with the service that is now being provided by the dermatology department at Aberdeen Royal Infirmary.

The issue of GP excision avoiding delay does not arise, as any lesion referred as a suspected melanoma will be seen by a specialist within 14 days. Many lesions referred urgently as suspicious are found to be benign on expert examination and do not require excision.

This problem is compounded by the issue that in many NHS Trusts, GPderived histopathology samples are immediately graded as routine, as GPs do not have a mandate to excise malignancy. This may incur waits as long as 6 weeks for the sample to be reported, whereas in secondary care the samples are graded as urgent and reported within 3 weeks in most trusts.

Of course trained GPs can capably excise small lesions on non-critical sites, as can specialist nurses, but many lesions do not require excision. Diagnosis and treatment planning are critical. Regrettably, the medical undergraduate curriculum and GP training underemphasise dermatology. Consequently, excellent skin lesion recognition skills are not universal. The British Association of Dermatologists lobbies for better training, and with the Primary Care Dermatology Society recently sent a joint letter to the Royal Colleges, Department of Health, and other parties advocating better skin lesion diagnostic training for all GPs.

Within the Measures Document for Skin Cancer there is a provision for GPs to integrate into the local multidisciplinary team structure as Model 2 practitioners, removing lesions that have been diagnosed by accredited members of the multidisciplinary team.

Recent revision of the 2006 skin cancer IOG allows suitably-qualified GPs to treat smaller well-defined basal cell carcinomas on trunk and limbs under LES/DES schemes subject to audit. However, we should reflect that melanoma is a potentially fatal cancer. Should it be treated on a casual basis by well-meaning generalists who are inevitably behind the curve on current best evidence? Most GPs will only see one melanoma every 3 or 4 years.

Best clinical outcomes are achieved in specific areas (whether fitting IUCDs, administering cognitive behavioural therapy, or through paediatric heart surgery) by healthcare workers who practice to current best evidence in teams and are accredited and audited. This also applies to skin cancer. We believe that one study showing that GPs were capable of doing simple excisions (setting aside the above point about punch and incisional biopsies that may invalidate even this finding) gives no grounds to overturn the current status quo. We believe the emphasis instead should be to improve both patient education, as well as GP and other healthcare workers' lesion recognition skills to achieve earlier diagnosis and better outcomes in melanoma.

The direction of travel in skin cancer management is to develop integrated community-based services within an multidisciplinary team structure, that ensures clinical governance and enhances patient safety. Many excellent examples of this model already exist in the UK.

\section{Stephen Hayes,}

GPwSI in Dermatology, Trustee, Primary Care Dermatology Society.

E-mail:nina@bad.org.uk

\section{Stephen Keohane,}

Consultant Dermatologist, Chair, Skin Cancer Sub-committee, British Association of Dermatologists.

\section{REFERENCE}

1. Murchie P, Sinclair E, Lee AJ. Primary excision of cutaneous melanoma: does the location of excision matter? Br J Gen Pract 2011; 61(583): 131-134.

DOI: $10.3399 /$ bjgp11X567162

\section{Primary excision of cutaneous melanoma}

In their paper Murchie et al pose the question of whether it matters if the excision of primary cutaneous melanoma is performed in primary care by GPs. ${ }^{1}$ We refute the conclusion that this is a way to expedite diagnosis or that it should lead to a change in guidelines. Their results should not be seen as providing commissioners with alternatives to referring all suspected melanomas for specialist assessment as recommended in current guidelines from National Institute of Health and Clinical Excellence and British Association of Dermatologists/British Association of Plastic Reconstructive and Aesthetic Surgeons updated last year..$^{2,3}$ Eight out of 11 studies of skin cancer excisions showed that clearance is more adequately achieved by dermatologists/specialists.

The data from 1991-2006 predate guidelines and modern skin cancer services with $21 \%$ being excised by general surgeons and only $15 \%$ by dermatologists. This is not generalisable to the rest of the UK or to our current practice. From the same population we have audit data from 2009 that reflect a change in practice with the introduction of a modern skin cancer service based on national guidelines. This has reduced waiting times with a reduction in primary care excisions and increased roles for dermatologists. There were a total of 130 melanomas in Grampian, Scotland, in 2009. Dermatologists diagnosed 60 (46\%), 43 (33\%) by plastic surgeons, 22 $(17 \%)$ by primary care, and 5 (4\%) from other sources. Of the 22 melanomas excised in primary care, $16 / 18$ were complete excisions. The remaining four melanoma specimens were incised, shaved, or curetted, in other words, incompletely excised. Dermatologists and plastic surgeons had complete excision rates of $84 \%$ and $89 \%$ respectively, excluding incision biopsies.

Of the 22 melanomas coming from 